\title{
Safety Belt Use, Ejection and Entrapment
}

\author{
James O'Day, MS \\ Robert E. Scott, MS
}

One in every five occupants thrown from a car receives fatal injuries. A motorist who uses a safety belt. in all probability. will not be thrown from the car during a crash. The rate of fatal injury for ejected occupants was found to be 40 times the rate for occupants not thrown from their cars, as determined from national accident sampling data. These data refute the popular notion that "being thrown clear" has survival benefit. In addition. there was no evidence that wearing a safety belt increased fatality risk from vehicle tire or submersion.

\section{INTRODUCTION}

Anecdotal accounts exist about a person's surviving an automobile crash because he/she was thrown clear of the vehicle. Such events do occur, and are often given noticeable publicity, for two reasons. First, such news offers people information they want to hear-that humans sometimes escape the awful consequences of dire and desperate circumstances. Second, such events are rare, and rarity (to at least some extent) is newsworthy.

Motorists whose information about auto accidents comes mainly from anecdotes may believe that using a restraint system such as safety belts is more dangerous than not using restraints. An indication of this was found in a 1982 survey of opinions held by licensed Michigan drivers. ' Half of these drivers feared that using a safety belt would increase their chance of being trapped in a car on fire or submerged in waterboth extremely rare events. To better understand the relationship between safety belt use in fatalities involving burning or submerged vehicles, and ejection and death, we analyzed data sets from several accident data files.

James O'Day is a Research Scientist and Interim Director. University of Michigan Transportation Research Institute, Ann Arbor.

Robert Scott is presently a retired Research Scientist from the University of Michigan, Ann Arbor, Ml.

This paper is based on an article published in the University of Michigan Transportation Research Institute's Research Review' (1984).

Address reprint request to James O'Day. University of Michigan, Transportation Research Institute, Ann Arbor, MI 48109. 
Table 1. Safety Belt Use and Consciousness After Crashes. NASS 1981 File.*

\begin{tabular}{lcc}
\hline $\begin{array}{c}\text { Postcrash } \\
\text { Condition }\end{array}$ & $\begin{array}{c}\text { Occupants Using } \\
\text { Safety Belts }\end{array}$ & $\begin{array}{c}\text { Occupants Not } \\
\text { Using Safety Belts }\end{array}$ \\
\hline Conscious & & \\
$\quad$ Number & $1,180.522$ & 8.439 .689 \\
$\quad$ Percent & $(99.45 \%)$ & $(98.67 \%)$ \\
Unconscious & & 109.281 \\
Number & 6.255 & $(1.28 \%)$ \\
Percent & $(.527 \%)$ & \\
\hline
\end{tabular}

*Columns do not total 100\% because occupants whose injuries were coded as "fatal" were not included in the "unconscious" category.

\section{POSTCRASH CONSCIOUSNESS}

To establish how often occupants are unconscious after a collision, the National Accident Sampling System (NASS) files at the University of Michigan Transportation Research Institute (UMTRI) were analyzed for the 1981 reporting year. ${ }^{2}$ Because NASS teams follow a strict sampling plan, the 5.987 cases collected during 1981 are a statistical microcosm representing the more than 6.2 million passenger car accidents involving 11.7 million occupants that occurred in 1981

The NASS file was selected for analysis not only because of its real-life mix of types, severities, and frequencies of accidents but because the in-depth investigations offer extensive detail on occupant injuries. Table 1 presents the results of computerized analyses relating safety belt use to postcrash consciousness of passenger car occupants.

Table 1 shows that occupants who used safety belts were much more likely to be conscious after an automotive accident than occupants who did not use safety belts. Only $0.527 \%$ of occupants in crashes (one of every 190 ) who were using safety belts were unconscious. In contrast. $1.28 \%$ of all occupants not using seat belts (one of every 78 ) were unconscious after the accident.

Among occupants using safety belts, those fatally injured totaled 316 , or $.027 \%$. The percentage of all nonbelted occupants fatally injured (.05) was almost twice as large as the percentage of all belted occupants (.027) who were fatally injured.

\section{EJECTION}

To examine how effective safety belts were in preventing occupants from being thrown from a car during an accident, three different data files were analyzed. One file, called the National Crash Severity Study, contains 11.386 passenger car accident cases investigated in 1977-1979 by teams in various areas of the United States. ${ }^{3}$ The second file contained all police-reported automotive accidents (some 300.000 cases) that occurred in Pennsylvania in 1979. The third file contained all police-reported automotive accidents (some 112,000 cases) that occurred in the state of Washington in 1981 .

The analyses of the three files showed only one case in which an occupant using safety belts was ejected. That occupant was in an old car so rusty that the bolts anchoring 


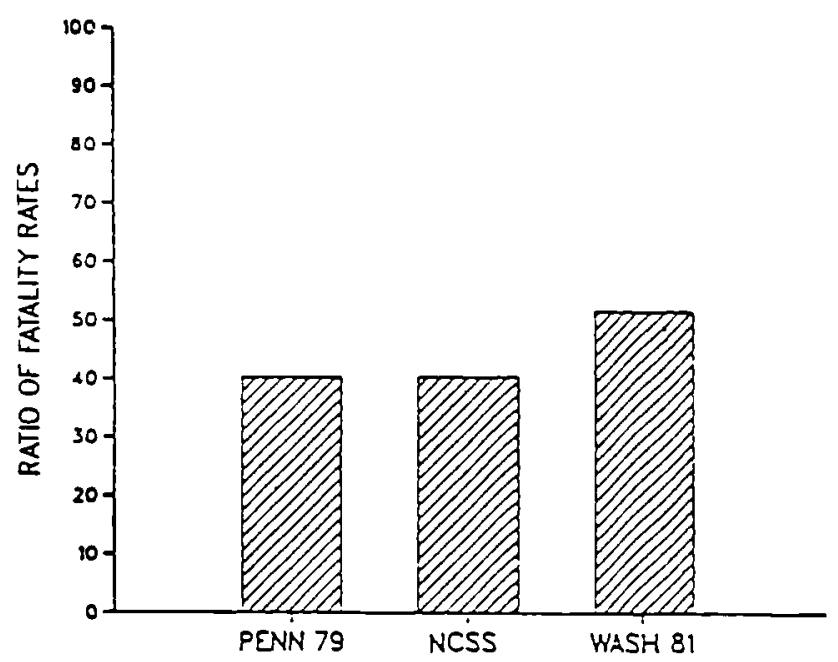

Figure 1. Ratio of fatality rates for ejectees to those for nonejectees.

the seat belt pulled through the floor. The analyses of the files also showed that (1) about one percent of all occupants were ejected. and (2) that 20 to 30 percent of all ejected occupants received fatal injuries, compared to only 0.5 percent of all occupants who remained inside their car. Those two rates of fatal injury are compared in Figure 1 .

As Figure I shows. the fatality rate for ejected occupants in the Pennsylvania and NCSS crashes was 40 times greater than for nonejected occupants. In the Washington crashes, the fatality rate for ejected occupants was 52 times greater.

The detailed case reports in the NCSS and NASS files revealed that many accidents involving ejection of an occupant were not crashes in which the car experienced sudden stopping or massive crushing, as with. for example. a collision with a fixed object or barrier of some kind. Cases involving ejection of an occupant were more often accidents in which the vehicle experienced an oblique impact or ran off the road into rough terrain, thereby triggering rollover or somersaulting motions. These occurrences often resulted in an occupant being thrown out through a door or window portal. The reports suggested that occupants restrained by a safety belt avoided serious injuries in a rollover accident, whereas occupants not using a safety belt often incurred serious head, neck, and spinal injuries.

To examine more closely the consequences of ejection, the computerized NCSS and NASS files were analyzed to identify and extract 121 particular cases involving occupant ejection. What was special about these cases was that the vehicle in each case had only two occupants--one in the driver's seat and one in the front passenger seatone of whom was ejected and one of whom was not ejected. The virtue of these cases was that each pair of occupants was subjected to the same crash severity and vehicle characteristics. As for being restrained, some of the nonejectees were using safety belts, but none of the ejectees were. The ejectees were about evenly divided between drivers and passengers. Among the 121 occupants who were thrown from the car, 27 of them died of their injuries. Among the 121 occupants who remained in the car, 11 died of their injuries. 
NON EJECTEES
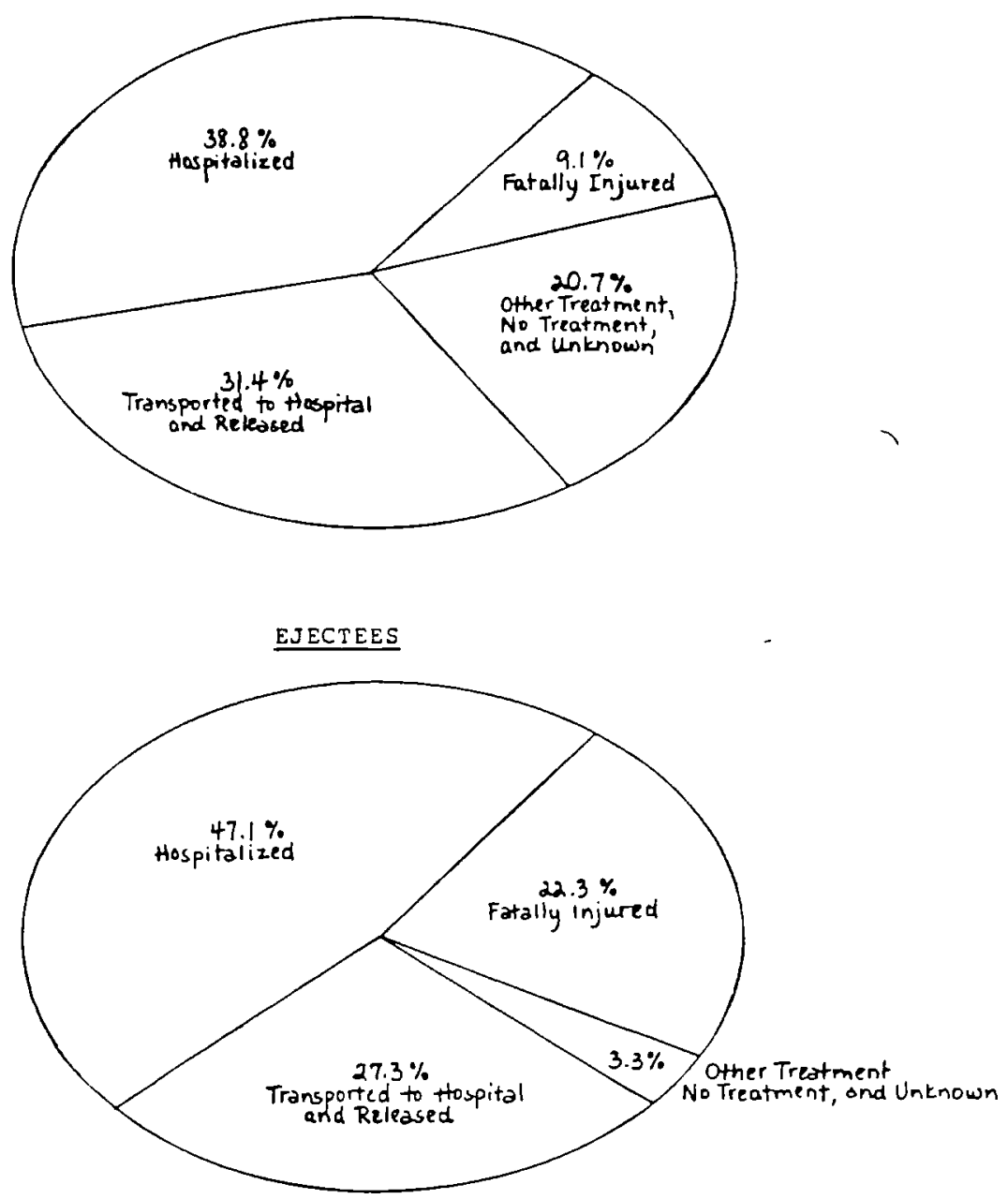

Figure 2. Medical treatments required by occupants in 121 accidents in which one front-seat occupant was ejected and one was not.

Figure 2 compares the extent of medical treatments required by the ejected and nonejected occupants.

As Figure 2 shows $9.1 \%$ of the occupants who remained inside the car received fatal injuries, compared to $22.3 \%$ of the ejectees. The nonejectees also had fewer injuries requiring hospitalization.

\section{POSTCRASH FIRES}

To examine fatal accidents in which a vehicle (cars, trucks and buses) caught fire, the FARS 1981 (Fatal Accident Reporting System) file was examined. ${ }^{+}$This file is a federal census of all fatal motor vehicle accidents occurring in the United States. In 
the FARS 1981 file, fatally injured passenger car occupants totaled 26,405 , with 951 occupants (3.6\%) sustaining fatal crash injuries in which a fire occurred in the involved car.

The file does not provide sufficient case detail to differentiate between fire-associated fatalities as a direct result of the vehicle fire. and crash fatalities from injuries unrelated to the vehicle fire. Only $2 \%$ of the 951 occupants in vehicle crashes involving fire were using safety belts. This compares with a safety belt use rate of 2.5 percent for all of the 25,454 fatally injured occupants in accidents not involving vehicle fire. This difference offers indirect evidence that safety belts help occupants remain conscious and able to remove themselves from a buming vehicle. These occupants are not in the FARS file as fatalities.

Postcrash fire and safety belt use were also examined in all accidents (fatal and nonfatal) that occurred in Michigan in the period 1980-1982. Michigan is one of the very few states that consistently report vehicle fires and fuel leakage. Because of this, Michigan data have been used to make national estimates of crash fire frequency for the National Highway Traffic Safety Administration.

The three years of Michigan data offer some additional indirect evidence of the efficacy of safety belt use. Of 3.060 occupants of passenger cars that caught fire during 1980-1982 in Michigan, 2,404 of them were not using safety belts, 332 were using safety belts, and. for the remaining 324 occupants, investigators did not establish whether they were using safety belts. Among all 2,404 occupants who were not using safety belts, $46(1.9 \%)$ received fatal injuries. Among 332 occupants who were using safety belts, only one occupant $(0.3 \%)$ received fatal injuries. If the rate of fatal injuries for occupants not using safety belts $(1.9 \%)$ were to be applied to the 332 occupants who were using safety belts. then six of those 332 restrained occupants could be expected to have received fatal injuries, in contrast to the single occupant who did receive fatal injuries. This is an indication that the use of safety belts probably helps occupants to remain conscious in a crash and to improve the chances of escaping a burning vehicle.

Such indirect evidence must, of course, be considered in conjunction with the fact that drivers who always wear safety belts tend to drive more cautiously than those who do not wear safety belts. Safety belt users tend to be involved in fewer accidents, and to be involved in less severe accidents, than drivers who do not wear safety belts at all. Thus at least part of the difference in the fatal injury rates discussed above needs to be attributed to differences in the severity of the crashes involving the belted and unbelted occupants. This issue has been addressed by the authors elsewhere. ${ }^{\mathrm{s}}$

\section{SUBMERSIONS}

Fatal accidents in which the passenger car has been submerged in water are infrequent. The FARS 1981 file indicates that of 26,405 total passenger car occupants fatally injured in 1981.364 of them $(1.4 \%)$ were in cars reported to have been immersed. Immersion is coded in the FARS file as the most harmful event associated with that vehicle, suggesting that the immersion was responsible for the fatal injury (perhaps by drowning).

Only five of the 364 submerison related fatality victims (1.37\%) were using safety belts, compared to 523 safety belt users $(2.0 \%)$ among the total of 26,037 nonsub- 
mersion-related fatalities. Thus, as with fire-associated fatalities, submersion-associated fatalities include a significantly lower percentage of safety belt users than is evident among the total population of fatally injured occupants. While this may not be evidence that use of safety belts prevents drowning, it does suggest that the use of safety belts does not increase the danger.

Health promotion has an important role to play in dispelling the myth that wearing safety belts increases the danger in vehicle submersions and fire. Fear of entrapment and belief that "being thrown clear" has protective value are still cited as reasons for not wearing safety belts." There is now strong epidemiologic evidence that wearing safety belts does not reduce the opportunities for survival in these rare incidents.

\section{References}

1. O'Day J. Filkins LD: Reviow of Telephone Survey of Michigan Residents on Seat Belt Usage and Atritudes, Fall, 1982 (Final Report).

2. National Center for Statistics and Analysis. National Accident Sampling Systems (NASS) National Highway Traftic Safety Administration. U.S. Deparment of Transportation. Washington. DC. 198I.

3. National Center for Statistics and Analysis. Mathematical Analysis Division. National Crash Severity Study (NCSS). National Highway Traffic Safety Administration. U.S. Depatment of Transportation, Washington. DC. 1977-1979.

4. National Center for Statistics and Analysis. Fatal Accident Reporting Systems (FARS), National Highway Traffic Safety Administration, U.S. Department of Transportation. Washington, DC, 1981.

5. O'Day J. Flora JD Jr: Alternative Measures of Restraint System Effectiveness: Interaction with Crash Severity Factors. Society of Automotive Engineers. Technical Report \#820798. Wartendale. PA.. June. 1982.

6. Lawrence Johnson \& Associates. Demographic. Simational, and Motivational Factors Associated with the Use of Safety Belts. Washington. DC. Contract No DTNH 22-80-C-17278 National Highway Traffic Safety Administration. 1982. 